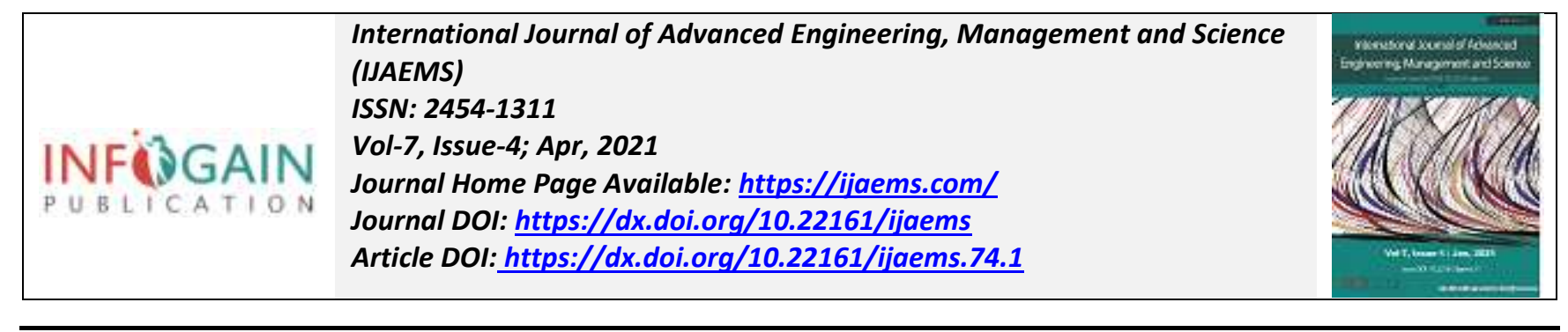

\title{
Influence of the Time of Year on the Reproductive Efficiency of Dazu Black and Mongolian White Cashmere Goats in Southwestern China
}

\author{
Ketian Wong*, Yongju Zhao, Zhongquan Zhao
}

Southwest University, College of Animal Science and Technology, Chongqing, China. *Corresponding Author

Received: 19 Jan 2021; Received in revised form: 25 Feb 2021; Accepted: 21 Mar 2021; Available online: 13 Apr 2021 (C)2021 The Author(s). Published by Infogain Publication. This is an open access article under the CC BY license (https://creativecommons.org/licenses/by/4.0/).

\begin{abstract}
With the aim to evaluate the reproductive performance of the Dazu Black (DZB) and Mongolian White Cashmere (IMCG) goats' races according to the times of the year. To integrate these reproductive traits, they were compared at different times of the year. At the same time, the prolific, fertility and fertility of herds were evaluated. Significant differences between epochs $(P<0.01)$ were determined for the fertility variable, although the fertility rate of DZB goats was higher (85.2\%) compared to IMCG (79.7\%), no significant differences were observed. The variable prolificity shows high values in the four measures, and no statistically significant differences were found for them. As for the number of births per epoch, the highest values were found in the spring for the DZB breed and summer for IMCG. Correlations showed average results with positive correlations of $56.60 \%$ for DZB and $62.26 \%$ for IMCG. The time of year influenced the number of offspring at birth negatively $(r-0.06)$, the highest number of births occurred in spring for DZB and in summer for MWC and the presence of double births prevailed in both races during the period evaluated. The Dazu Black and Mongolian White Cashmere goats have defined characteristics that have modeled the genetic and phenotypic structure as a standard for each breed through environmental influence and cultural practices. This aspect demonstrates the adaptation and rusticity of goats and their ability to consume and take advantage of available foods. The sample size, distribution and methodology used in this research makes it possible to conclude that DZB goats and IMCG are a valuable genetic resource for adaptation, rusticity and productive efficiency.
\end{abstract}

Keywords-Prolific, fertility, traits, reproductive, genetic.

\section{INTRODUCTION}

Knowledge of the reproductive strategies of goats and the identification of the main environmental factor responsible for the annual cycle of reproduction in males and females is necessary to manipulate their reproductive activity and have the opportunity to produce milk, cheese, and goats all year round (Chemineau et al., 2007).

Fertility, prolificity, and embryonic mortality are parameters to consider when conducting studies characterizing the reproductive efficiency of a goat herd (Bedos et al., 2010).
In sheep and goat production, fertility is defined as the percentage of brown females relative to the total number of females exposed to a soaking stone, and prolificity is defined as the percentage of offspring born concerning the total number of brown females. Births are characteristics of great economic importance that have an impact on the number of lambs available to producers, both for sale and replacement of the same population (Delgadillo et al., 2004). 


\section{MAIN GOAL}

Evaluate the reproductive performance of the DZB and IMCG races according to the times of the year.

\section{MATERIALS AND METHODS}

The breeding behavior for both goats' breeds between the years $2008-2018$ was recorded. The study used a database, which featured a sample of 709 birthing records of Dazu Black (475) and Mongolia White Cashmere (234) from "Black Goat Etymological Conservation Farm", at Southwest University, Chongqing, China. The information concerning the females, as well as the date and type of the births (single, double, triple, or four offspring), parity, the period of a year, number of females and males born alive, and deaths in the period analyzed were recorded. The response variables of this experiment were fertility rate (F $\mathrm{s}$ number of goats brown/number of goats exposed x 100), and prolificity (P s number of goats born/number of goats brown $\mathrm{x}$ 100). The interval between deliveries (date of last birth- previous due date) was calculated. With the declared interval between births, fertility was calculated - Fertility rate $\mathrm{x}$ Prolificity / Interval between births.

The results obtained were statistically analyzed using the Chi square test, while prolificity was analyzed using variance analysis (ANDEVA) by least squares for a completely random design. In the case of the variables of time of year, parity, sex, number of births and deaths in the period covered by the aforementioned years. In all cases, the Statgraphics Centurion statistical package was used, by comparison of proportions.

\section{RESULTS AND DISCUSSION}

In table 1 it is shown the fertility values expressed as $\%$ of partition, fertility, and prolificity, depending on the time of the year: winter, spring, summer, and autumn.

Considering that the factors used in this work were mainly the age of the mothers and their parity, a significant interaction was found between these two variables. From the former, it can be said that both factors behave dependently in terms of their influence on the percentages of actual and observed fertility.

Table 1. Fertility rates for different times of the year

\begin{tabular}{|lllll|}
\hline Time of year & Race & Fertility rate & Fertility & Prolificity \\
& & & & \\
\hline Winter & DZB & 0.91 & 0.98 & 1.97 \\
& IMCG & 0.78 & 0.80 & 2.02 \\
Spring & DZB & 0.83 & 0.94 & 2.12 \\
& IMCG & 0.70 & 0.75 & 2.02 \\
Summer & DZB & 0.84 & 0.89 & 1.98 \\
& IMCG & 0.89 & 0.78 & 2.00 \\
Autumn & DZB & 0.83 & 0.87 & 1.92 \\
& IMCG & 0.82 & 0.66 & 2.06 \\
\hline Average & & 0.81 & 0.83 & 2.01 \\
\hline
\end{tabular}

Significant differences between epochs (c 2 x 13.11, P< $0.01)$ were determined for the fertility variable, although the fertility rate of DZB goats was higher $(85.2 \%)$ compared to IMCG (79.7\%), no significant differences was observed (Square Chi; $p$ > 0.05). Both results were higher than what is mentioned by Vera et al. (2003) in goats raised in the tropics, and fed with supplemented corn oil, which reported higher fertility rate $(73.3 \%)$.

Prolificity shows high values for the four periods of time considered, finding no statistically significant differences. The prolificity similarities of goats, from this study, are similar to that recorded by Duricic et al. (2012), who reported an average of 1.96 and 1.98 for Boer goats in a moderate climatic zone.

For the goats of this research, prolificity is superior to that reported by Haniza et al. (2017) who mention that nutrition and mineral salts enrich follicular fluid, whereby its action on follicular cells improves follicular dynamics and ovulation. Hence, they have a greater number of large follicles that can potentially ovulate and thus improve prolificity.

Zhao et al. (2018) in a study of the breed Dazu Black found an interval between births of 237 days, in this research this parameter was quantified in 284 days for the race Dazu 
Black and 306 days for Mongolia White Cashmere. This could have influenced fertility values to decrease from the prolificity that was higher.

Fertility rates are lower than those determined by Kaliber et al. (2016) for similar systems in northern Chile, which has similar temperatures to southwestern China.
As can be seen in figure1, the highest values were found in the spring for the Dazu Black breed and summer for Mongolia White Cashmere. These values were. This decrease could be due to a decrease in food availability, or because animals are at a recovery or rest stage as a result of the high demands of the year evaluated, since this is an experimental unit and it is the of studied by all students and teachers in the university.

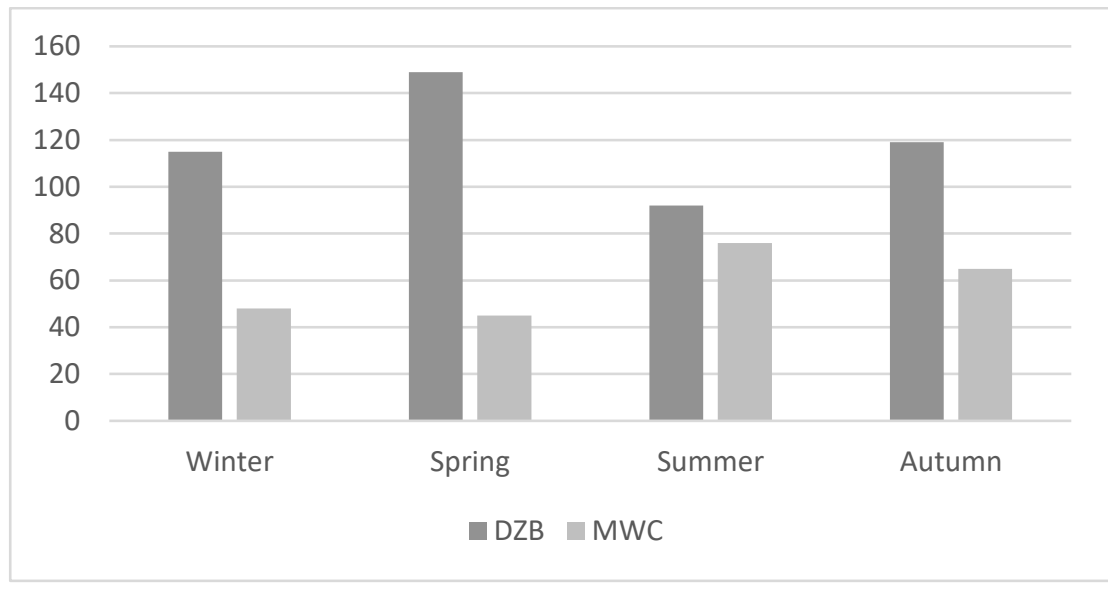

Fig.1: Births according to the time of year.

According to Banerjee et al. (2016), the time of the year where the best productive results are obtained varies a lot according to the area where livestocks are raised, since reproductive seasonality depends on a lot of factors, such as light and temperature.
Table 2 shows the number of births according to the time of year in both races.

Table 2. Birth behavior according to the time of year by race.

\begin{tabular}{|c|c|c|c|c|c|c|}
\hline $\begin{array}{l}\text { Time of } \\
\text { year }\end{array}$ & Races & Single & Double & Triplets & Quadruplets & $\begin{array}{l}( \pm \mathrm{ES}) \quad(\mathrm{P}- \\
\text { value })\end{array}$ \\
\hline \multirow[t]{2}{*}{ Winter } & DZB & $25(17.8) b$ & 59(55.7)a & $24(21.0) \mathrm{b}$ & $6(5.0) c$ & $0.08 * *$ \\
\hline & IMCG & $10(20.8) b$ & $27(58.3) \mathrm{a}$ & 11(22.9)b & $0(-) c$ & $0.16^{*}$ \\
\hline \multirow[t]{2}{*}{ Spring } & DZB & $29(19.0) \mathrm{b}$ & $78(51.3) \mathrm{a}$ & $42(27.6) b$ & $3(1.97) \mathrm{c}$ & $0.01 * *$ \\
\hline & IMCG & $10(21.7) b$ & $26(56.5) \mathrm{a}$ & $9(19.5) b$ & $1(2.17) \mathrm{c}$ & $0.14 *$ \\
\hline \multirow[t]{2}{*}{ Summer } & DZB & $24(26.2) \mathrm{b}$ & $48(52.2) \mathrm{a}$ & $17(18.5) b$ & $3(3.2) \mathrm{c}$ & $0.07 *$ \\
\hline & IMCG & $22(28.9) b$ & $34(44.7) a$ & $18(23.6) b$ & $2(2.6) c$ & $0.03 *$ \\
\hline \multirow[t]{2}{*}{ Autumn } & DZB & $37(31.1) \mathrm{ab}$ & $55(46.2) \mathrm{a}$ & $26(21.8) b$ & $1(0.8) \mathrm{c}$ & $0.11 *$ \\
\hline & IMCG & $13(20.0) \mathrm{b}$ & $35(53.8) \mathrm{a}$ & $17(26.2) \mathrm{b}$ & $0(-) c$ & $0.04 * *$ \\
\hline
\end{tabular}

As for the number of births according to the percentages of single, double, triple, and quadruple, we can see that double births showed significant differences in all seasons of the year, with the percentage between $44.7 \%$ and $58.3 \%$ respectively. While in this study the births with four or more young were lower at all times of the year.

In a study conducted by Zhao et al. (2018) the percentages of singletons, twins, triplets, and quadruplets born were $1.98,47.27,40.02$, and $10.29 \%$, respectively. These results 
are similar to our findings. Other authors (Duricic et al., 2012; Oliveira et al., 2017) in a study of medium litter sizes of black goats Dazu Black, determined that this type of birth was the highest among the breeds of goats reported.

Hernández et al. (2002), in a study in Creole goats and halfbreeds foun that the percentage of multiple births appears to be linked to the females' adult weight. . The percentage of multiple births in Creole breeds was $46.5 \%$. The highest percentages (56.6 to $84 \%$ ) are reported for Boer goats in South Africa, Damascus goats in Lebanon, and Barbari goats in India (Luque, 2011). The lowest percentages (32\%) has been reported for Malabari goats in India and Uganda respectively.

There were no differences in sex between them, so the proportion was $51 / 49 \%$ in both races. In the case of births, there is greater evidence in the Dazu Black breed, but this is determined by the number of individuals in each race, which is higher in number compared to the Mongolia White Cashmere.

Table 3. Simple regression between the number of birthing rates, decaying from the time of year.

\begin{tabular}{|llllll|}
\hline Indicators & EE & r & R2 (\%) & P Value \\
\hline Time of year/Number of birth pups & 0.74 & -0.03 & 0.13 & NS \\
\hline Linear Equation Y-a+b*X & Number of birth pups & $=2.11237-0.0249145^{*}$ Time of year \\
\hline
\end{tabular}

It can be observed that there was no significant difference between the time of year and the number of births. According to Haniza et al. (2017), there are several factors, genetic and environmental, that can affect the reproductive capacity of herds. On the other hand, many factors affect these indicators such as nutrition and management that can significantly affect reproductive performance. Rhone et al.
(2013) also determined that the efficiency of reproduction is determined by many different processes, including age in the first gestation, birth interval, birth type, and litter sizes at birth.

Table 4 shows the behavior of young born alive by births relative to the time of year, during the period evaluated.

Table 4. Simple regression between the number of live births and the time of year.

\begin{tabular}{|llllll|}
\hline Indicators & EE & r & R2 (\%) & P Value \\
\hline Time of year/Number of live births & 0.02 & -0.06 & 0.31 & $*$ \\
\hline Linear Equation Y-a+b*X & \multicolumn{2}{l}{ Number of live births=2.15475-0.045627* Time of Year } \\
\hline
\end{tabular}

The number of live births showed differences from the time of year $(\mathrm{p}<0.05)$. The correlation coefficient is $\mathrm{r}-0.06$, so it indicates a weak, negative relationship. So, it is determined at $31 \%$ of these births by the time of year. This rate expresses the productive potential of a breed and is conditioned on management and feeding factors.

In Tables 5 and 6, the correlation between the years and the reproductive indicators studied are shown.

Table 5. Correlations of the years and times of the year, with the reproductive indicators, studied for the Dazu Black breed.

\begin{tabular}{|lllllllll|}
\hline DZB & Year & Birth & Female & Male & B- Alive & Dead & B W & Parity \\
\hline Year & 1 & & & & & & \\
Birth & -0.04 & 1 & & & & & & \\
Female & -0.06 & $0.52 * * *$ & 1 & & & & \\
Male & 0.02 & $0.42 * * *$ & $-0.54 * * *$ & 1 & & & \\
B- Alive & -0.05 & $0.97 * * *$ & $0.50 * * *$ & $0.42^{* * *}$ & 1 & & & \\
Dead & 0.04 & $-0.14^{*}$ & -0.03 & $-0.09 *$ & $-0.36^{* * *}$ & 1 & & \\
BW & $0.18^{* * *}$ & $-0.12^{* *}$ & -0.01 & $-0.12^{* * *}$ & -0.05 & $-0.28 * * *$ & 1 & \\
Parity & $0.11 * *$ & $0.29 * * *$ & $0.14 * *$ & $0.13^{* *}$ & $0.29 * * *$ & -0.08 & $0.23 * * *$ & 1 \\
\hline & Month & Birth & Female & Male & B- Alive & Dead & B W & Parity \\
\hline Month & 1 & & & & & & &
\end{tabular}




\begin{tabular}{|lcllllllll|} 
Female & -0.03 & $0.52 * * *$ & 1 & & & & & \\
Male & -0.04 & $0.42 * * *$ & $-0.54 * * *$ & 1 & & & & \\
B- Alive & -0.07 & $0.97 * * *$ & 0.50 & $0.42 * * *$ & 1 & & & & \\
Dead & -0.01 & $-0.14 * *$ & -0.03 & $-0.09 *$ & $-0.36 * * *$ & 1 & & & \\
BW & -0.04 & $-0.12 * *$ & -0.01 & $-0.12 * *$ & -0.05 & $-0.28 * * *$ & 1 & \\
Parity & 0.04 & $0.29 * * *$ & $0.14 * *$ & $0.13 * *$ & $0.29 * * *$ & -0.08 & $0.23 * * *$ & 1 \\
\hline
\end{tabular}

As it can be seen in the table above, univariate analyses using fixed-effect models showed that the year's interaction with reproductive indicators showed weak and negative effects for traits in the number of offspring born and females born in each birth. The number of offspring born concerning sex also yielded significant differences with moderately strong and positive correlations for both sexes $(p \leq 0.001)$, with correlations between males and females born in the period studied. On the other hand, the results of deaths based on the number of births showed weak and negative results, which mean that as births increase, deaths decreased at the stage analyzed. Birth weight relative to years showed a weak and positive correlation with statistical differences,

Table 6. Correlation of the years and time of the year, with the reproductive indicators, studied for the Mongolian white

Cashmere breed
Cante 6. Correlation of the years and time of the year, with the reproduct as well as the number of births and deaths. As for parity, it can be shown that there are statistical differences for most indicators under study except for deaths that had a negative correlation

As for the time of year, weak and negative correlations can be observed in most cases. Significant differences ( $\mathrm{p} \leq 0.001$ ), as well as the birth weight concerning the number of births, with weak and negative correlation, are evident for traits in the number of births $(p \leq 0.001)$, as the number of births increases. Like parity in I show significant differences for most of the characters studied.

\begin{tabular}{|c|c|c|c|c|c|c|c|c|}
\hline IMCG & Year & Birth & Female & Male & B- Alive & Dead & B W & Parity \\
\hline Year & 1 & & & & & & & \\
\hline Birth & 0.08 & 1 & & & & & & \\
\hline Female & 0.01 & $0.41 * * *$ & 1 & & & & & \\
\hline Male & 0.07 & $0.45 * * *$ & $-0.62 * * *$ & 1 & & & & \\
\hline B-Alive & 0.08 & $0.94 * * *$ & $0.40 * * *$ & $0.41 * * *$ & 1 & & & \\
\hline Dead & -0.02 & 0.08 & 0.01 & 0.05 & $-0.22 * * *$ & 1 & & \\
\hline BW & 0.11 & $-0.34 * * *$ & $-0.18 * *$ & -0.11 & $-0.30 * * *$ & -0.09 & 1 & \\
\hline Parity & $0.53 * * *$ & $0.22 * * *$ & 0.11 & 0.08 & $0.19 * *$ & 0.08 & $0.14 *$ & 1 \\
\hline & Month & Birth & Female & Male & B-Alive & Dead & B W & Parity \\
\hline Month & 1 & & & & & & & \\
\hline Birth & -0.01 & 1 & & & & & & \\
\hline Female & 0.01 & $0.41 * * *$ & 1 & & & & & \\
\hline Male & -0.01 & $0.45 * * *$ & $-0.62 * * *$ & 1 & & & & \\
\hline B-Alive & -0.01 & $0.94 * * *$ & $0.40 * * *$ & $0.41 * * *$ & 1 & & & \\
\hline Dead & 0.04 & 0.08 & 0.01 & 0.05 & $-0.22 * * *$ & 1 & & \\
\hline BW & 0.06 & $-0.34 * * *$ & $-0.18 * *$ & -0.11 & $-0.30 * * *$ & -0.09 & 1 & \\
\hline Parity & 0.02 & $0.22 * * *$ & 0.11 & 0.08 & $0.19 * *$ & 0.08 & 0.08 & 1 \\
\hline
\end{tabular}

As for the Mongolian White Cashmere breed, we found a weak and positive correlation for most of the indicators evaluated. It is important to highlight live births, birth weight, and parity as variables with statistically significant difference ( $p \leq 0.001)$. By the time of year, these were very similar, so it is emphasized that the birth weight a weak and 
negative correlation in terms of the number of births sex, and live births.

\section{CONCLUSIONS}

- The results found in this research show that the goats under study have a good reproductive efficacy that is $83 \%$ fertility; 81 fertility and 2.01 prolificity, which is very

important when it is considered that these are animals bred for research purposes and without any special food supplementation.

- The presentation of double births is higher compared to single, triple, and quadruple births at all times of the year.

- The time of year influences $31 \%$ of births that occurred during the period studied.

\section{REFERENCES}

[1] Banerjee, D., Upadhyay, R. C., Chaudhary, U. B., Kumar, R., Singh, S., Ashutosh, Das, Das, T. K. and De, S. (2015). Seasonal variations in physio-biochemical profiles of Indian goats in the paradigm of hot and cold climate. Biological Rhythm Research, 46(2): 221-236.

[2] Bedos, M., Flores, J.A., Fitz-Rodríguez, G., Keller, M., Malpaux, B., Poindron, P., Delgadillo, J.A. (2010). Four hours of daily contact with sexually active males is sufficient to induce fertile ovulation in anestrous goats. Hormones and Behavior. 58: 473-477.

[3] Chemineau, P., Malpaux, B., Brillard, J.P., Fostier, A. (2007). Seasonality of reproduction and production in farm fishes, birds and mammals. Animal. 1:419-432.

[4] Delgadillo, J.A., Cortez, M.E., Duarte, G., Chemineau, P., Malpaux, B. (2004). Evidence that the photoperiod controls the annual changes in testosterone secretion, testicular and body weight in subtropical male goats. Reproduction, Nutrition and Development. 44: 183-193.

[5] Duricic, D., Grizelj, J., Dobranic, T., Harapin, I., Vince, S., Kocila, P. and Samardzija, M., (2012). Reproductive performance of Boer goats in a moderate climate zone. Vet. Arh., 82: 351-358.

[6] Haniza, M.Z.H., Ta, M.M. and Husni, I., (2017). Reproductive performance of different goat breeds in Malaysia. Indian J. Anim. Res., 590: 14. https://doi.org/10.18805/ijar.v0iOF.7002

[7] Hernández, Z. J. S., Franco, G. F. J., Herrera, G. M., Rodero, S. E., Sierra, V. A. C., Bañuelos, C. A. y Delgado, J. V. (2002). Estudio de los recursos genéticos de México: características morfológicas y morfoestructurales de los caprinos nativos de Puebla. Universidad de Córdoba. Córdoba. España. Recuperado de http://www.redalyc.org/articulo.oa?id=49519408.

[8] Kaliber, M., Koluman, N., and Silanikove, N. (2016). Physiological and behavioral basis for the successful adaptation of goats to severe water restriction under hot environmental conditions. Animal, 10(1): 82-88.
[9] Luque, M. (2011). Caracterización y evaluación de las razas caprinas españolas deorientación cárnica. (Tesis doctoral). Universidad de Córdoba, España.

[10] Oliveira, J.D., Fonseca, J.F., Souzafabjan, J.M., Esteves, L.V., Feres, L.F. and Rodrigues, C.A. (2017). Protected fatty acid supplementation during estrus synchronization treatment on reproductive parameters of dairy goats. Anim. Sci. J., 88: 254-258. https://doi.org/10.1111/asj.12640

[11] Sttiltical, Centurion Corp. (2001). STATGRAPHICS CENTURION For Windows 5.1.

[12] Zhao Zhongquan, Tianyuan Yang, Lei Qiao, Qijie He and Zinuo Dai. (2018). Reproductive Characteristics of Dazu Black Goats, a Newly Discovered Chinese Indigenous Breed Resource with High Litter Sizes. Chongqing Engineering Research Center for Herbivores Resource Protection and Utilisation, Southwest University, Chongqing, 400716, China. 2018. 